Mario L. Ruz, Juan Garrido, Francisco Vázquez. Educational Tool for the Learning of Thermal Comfort Control based on PMV-PPD Indices, Computer Applications in Engineering Education, Volume 26, Issue 4, 2018, pp. 906-917, ISSN 1099-0542, https://doi.org/10.1002/cae.21934 (https://onlinelibrary.wiley.com/doi/abs/10.1002/cae.21934)

\title{
EDUCATIONAL TOOL FOR THE LEARNING OF THERMAL COMFORT CONTROL BASED ON PMV-PPD INDICES
}

Mario L. Ruz, Juan Garrido, Francisco Vázquez

University of Cordoba, Department of Computer Science and Numerical Analysis, Campus de Rabanales, 14071, Cordoba, Spain.

\begin{abstract}
In this paper, an interactive educational tool designed for the learning of thermal comfort concepts is presented. Thermal comfort is one of the fundamental aspects of indoor environmental quality and energy savings in buildings. Comfort-based control and energy management constitute an important emergent sub-discipline of engineering studies. The developed tool allows for the definition of the thermal model of a house. Based on this model, thermal comfort is estimated through the predicted mean vote (PMV) and predicted percentage dissatisfied (PPD) indices, and energy consumption is also calculated. The tool can communicate through Modbus TCP/IP protocol, providing external connectivity and data collection from the different sensors available in a building management system (BMS). In this way, it is possible to calculate in real-time the aforementioned comfort indices and propose corrective control indications to maintain the indoor-air conditions inside the optimal comfort range. A simple control strategy that can be applied to conventional HVAC systems is also addressed. The tool is available for degree students in control engineering. A survey was performed to evaluate the effectiveness of the proposed tool.
\end{abstract}

Keywords: Educational tool; thermal comfort; modeling and simulation; comfort-based control

\section{INTRODUCTION}

Nowadays, environmental impacts, industrial activities, urban patterns or the use of air conditioning systems have led to an increase of the energy demands in buildings [1]. Currently, this area represents more than $40 \%$ of the energy consumption in most countries. European Union has promoted new directives to improve the energy performance in buildings to reduce the energy consumption [2], [3]. Industrial systems such as heating, ventilation and air conditioning (HVAC) systems, are responsible for over $50 \%$ of the total energy consumption of 
a building [4], [5]. Traditionally, HVAC systems accomplish thermal comfort by regulating temperature of indoor air at predetermined temperature. However, reaching this temperature may not be necessary to make occupants comfortable [6].

To solve this problem, many researches related to comfort-based control have been studied [7]-[9], which could be a possible solution to the problem of energy consumption in buildings. Many of these researches were based on the predicted mean vote (PMV) and predicted percentage dissatisfied (PPD), which are mostly used as comfort indices [8].

Considering the above context, there arises a need of training new engineering students with a solid background and knowledge in thermal comfort and energy management. These technicians could put into practice the obtained advances in research environment-related with thermal comfort control. In addition, the dynamic modeling and simulation are considered basic tools to strengthen the theoretical aspects in the engineering teaching [10]. Both tools are included within the constructivist methodology based on problem-based learning (PBL) paradigm to guide the search for knowledge [11], [12]. PBL is a student-centered instructional strategy. This approach employs a problem situation to guide the learning activities on a need-to-know basis.

The aim of this paper is to present a new interactive educational software tool, called CB-GUI (Comfort-Building Graphical User Interface) for the calculation, analysis and simulation of thermal comfort. The developed tool uses the well-known PMV/PPD model [13] to estimate the thermal comfort conditions, and is based on the Matlab/Simulink environment, which is currently widespread in the field of engineering education and the most students are familiar with it.

Software tools similar to CB-GUI have been developed. For example, Thermal Comfort Tool ASHRAE-55 [14], [15] is a web-based tool that allows designers and other practitioners to perform thermal comfort calculations according to the ASHRAE-55 standard [16]. Among its main features, this software tool allows to choose between the two comfort models allowed by the aforementioned standard, which are the PMV/PPD method and the adaptative method. Moreover, an ankle draft risk model, based on the works [17], [18], has been also implemented. With this model, the predicted percentage dissatisfied on draft at ankle level as a function of 
PMV and air speed at can be evaluated. Another interesting tool is Climate Consultant [19], which assists in designing buildings that are more energy-efficient and sustainable, by means of passive heating and cooling strategies, including fan-forced ventilation. The different heatrelated strategies are analyzed as a function of available climate data for a particular location, allowing for the most effective strategy to be selected. The ASHRAE-55 standard is also considered.

There are also complete simulation environments by which models of many different engineering domains can be implemented. For example, a complete simulation program for modeling energy consumption (for heating, cooling, ventilation, lighting, etc.) in buildings is EnergyPlus $^{\mathrm{TM}}$ [20]. This is an open-source and cross platform software that was initially intended to size appropriate HVAC equipment and optimize energy performance. Considering the purposes of this work, the last available version of EnergyPlus ${ }^{\mathrm{TM}}$ allows the use of different thermal comfort models as well as a large number of built-in HVAC control strategies. Thus, this software could be specifically used for the development of a complex building thermal analysis with thermal comfort models. This allows to perform an energy analysis and simultaneously determine if a specific HVAC control strategy will be sufficient for the occupants to be thermally comfortable. Another example is the commercial modeling and simulation environment Dymola [21]. This tool is based on the Modelica language [22]. Dymola provide access to libraries which enable the mathematical modelling of thermal comfort within buildings, ships or aircraft cabins [23], [24].

These tools provide valuable information for both students and researchers. However, to the authors' knowledge, there is no developed tool which encompasses specifically energy, thermal comfort, and control concepts from an educational point of view. This is one of the main contributions of the proposed tool. In addition, CB-GUI adds the possibility of applying control strategies based on the PMV and PPD indices either to a thermal model or to a real building through Modbus TCP/IP protocol, providing external connectivity and data collection from the different sensors available in a BMS system. This feature helps students understand the link between energy consumption, human comfort, and control strategies. 
The paper is structured as follows: Section 2 presents the theoretical framework of thermal comfort. Section 3 describes the main features of the software tool. In addition, the set of components and equations that describe the implemented house thermal model are detailed. Section 4 shows the intended use of the tool for students by means of an illustrative example, where a control method based on PMV is proposed and compared with conventional fixed temperature settings. Section 5 discusses the evaluation methodology and the results obtained. The paper ends with some concluding remarks and considerations about future works.

\section{THERMAL COMFORT BACKGROUND}

Thermal comfort is defined by American standard ASHRAE 55 [16] as the condition of mind that expresses satisfaction with the thermal environment. Thermal comfort can be influenced by different kinds of physical, physiological or psychological processes [25].

There are two classical approaches for the thermal comfort modeling that can be used [26]: heat balance models based on laboratory studies and adaptive models based on field studies. The first one is the classical work of Fanger [13], related with thermal sensation to the existence of heat balance by observing a large number of people in laboratory experiments. The second approach is based on the findings of surveys of thermal comfort conducted in the field [27]. In this work, the thermal comfort model employed is defined by applying Fanger's studies, which are the basis for the two main international standards currently used for assessing thermal comfort in buildings $[16,12]$.

Fanger's method predicts thermal comfort on the basis of a set of parameters and empirical equations of the heat transferred between the human body and the environment [29]. This analysis results in an index that predicts the thermal sensation scale. The resulting index, named the Predicted Mean Vote (PMV), is a well-recognized comfort parameter used for measuring comfort levels inside buildings. PMV predicts the mean response regarding thermal sensation of a large group of people exposed to certain thermal conditions for a long time [30]. PMV depends on six parameters: the metabolic heat rate, $M$ (met), where $1 \mathrm{met}=58.2 \mathrm{~W} / \mathrm{m}^{2}$; the clothing insulation, $I s_{c l}$ (clo), where $1 \mathrm{clo}=0.155 \mathrm{~m}^{2}{ }^{\circ} \mathrm{C} / W$ is a unit used to express the 
thermal insulation provided by garments and clothing ensembles; the indoor air temperature, $T_{\text {ain }}\left({ }^{\circ} \mathrm{C}\right)$; the mean radiant temperature, $T_{m r}\left({ }^{\circ} \mathrm{C}\right)$; the indoor air velocity, $v_{\text {ain }}(\mathrm{m} / \mathrm{s})$, and the air relative humidity, $R_{h}(\%)$, which is the ratio of the partial pressure of the water vapor in the air to the saturation pressure of water vapor at the same temperature. PMV is calculated by means of equation (1), where $L$ represents the thermal load in the human body $\left(W / m^{2}\right)$, and $M$ the metabolic rate, as mentioned before. The value of PMV index is a seven-point thermal sensation scale, as shown in Table 1.

$P M V=\left(0.303 e^{-0.036 M}+0.028\right) L$.

The thermal load in the human body can be estimated using expression (2).

$L=(M-W)-0.0014 M\left(34-T_{\text {ain }}\right)-3.05 \cdot 10^{-3}\left[5733-6.99(M-W)-p_{\text {ain }}\right]$
$-0.42(M-W-58.15)-1.72 \cdot 10^{-5} M\left(5867-p_{\text {ain }}\right)-39.6 \cdot 10^{-9} F_{c l}\left[\left(T_{c l}+273\right)^{4}\right.$
$\left.-\left(T_{m r}+273\right)^{4}\right]-F_{c l} h_{c}\left(T_{c l}-T_{\text {ain }}\right)$,

where

$$
\begin{aligned}
& \quad T_{c l}=35.7-0.028(M-W)-0.155 I s_{c l} \cdot\left[39.6 \cdot 10^{-9} F_{c l}\left[\left(T_{c l}+273\right)^{4}-\left(T_{m r}+273\right)^{4}\right]\right. \\
& \left.+F_{c l} h_{c}\left(T_{c l}-T_{a i n}\right)\right]
\end{aligned}
$$

$h_{c}= \begin{cases}2.38\left(T_{\text {cl }}-T_{\text {ain }}\right)^{0.25}, & B \geq 12.1 \sqrt{v_{\text {ain }}} \\ 12.1 \sqrt{v_{\text {ain }}}, & B \leq 12.1 \sqrt{v_{\text {ain }}}\end{cases}$

$F_{c l}=\left\{\begin{array}{cl}1.0+0.2 I s_{c l}, & I s_{c l} \leq 0.5 \text { clo } \\ 1.05+0.1 I s_{c l}, & I s_{c l}>0.5 \text { clo. }\end{array}\right.$

$W$ is the external work $\left(W / m^{2}\right)$, and is normally assumed around zero [15], [16]; $p_{\text {ain }}$ is the partial water vapour pressure in the air $\left(P_{a}\right) ; T_{c l}$ is the clothing surface temperature $\left({ }^{\circ} \mathrm{C}\right) ; h_{c}$ is the convective heat transfer coefficient $\left(W /{ }^{\circ} \mathrm{C} \mathrm{m}^{2}\right)$; and $F_{c l}$ the clothing area factor (-). It is recommended that the value of PMV should lie within the range of $[-0.5,0.5]$ to ensure indoor thermal comfort [30]. On the other hand, associated with this parameter is the Predicted Percentage Dissatisfied (PPD). This index establishes a quantitative prediction of the 
percentage of thermally dissatisfied people who feel too cool or too warm. Mathematically, the relationship between PMV and PPD is expressed as follows:

$P P D=100-95 \exp \left[-\left(0.03353 P M V^{4}+0.2197 P M V^{2}\right)\right]$

For a PMV index inside the thermal comfort range around zero, approximately $5 \%$ of the people are dissatisfied with the thermal environment. The graphical relationship between PPD and PMV is shown in Figure 1.

\section{$<$ INSERT TABLE I HERE $>$ $<$ INSERT FIGURE 1 HERE $>$}

PMV considers not only indoor air parameters but also physical activity. There are other indices that allow the evaluation of thermal sensation and comfort, such as the Givoni diagrams [31], the operative temperature [16] and adaptive indices [32]. A detailed review of the most popular thermal comfort models and methods for assessing thermal comfort in buildings, as well as the future perspectives, is carried out in [29].

\section{MATERIAL AND METHODS}

\subsection{House thermal model}

A simple house thermal model with a heating subsystem is used to facilitate the students the understanding of thermal comfort and energy performance in buildings. This section describes the thermal model used in the developed application. Control based on thermal comfort indices is also addressed. The implemented model is based on [33], [34]. The house model exchanges heat with the environment through its walls, roof, and windows. Each path is simulated as a combination of thermal conduction, thermal convection, and thermal mass. Regarding the heating subsystem, a constant air flow rate $\dot{m}(\mathrm{~kg} / \mathrm{s})$ is considered, which is commanded by a thermostat. The thermostat models a hysteresis and allows fluctuations around a desired room temperature. If the air temperature drops below a specified lower set-point, the thermostat turns on the heater. The heat flow rate into the room, $\dot{Q}_{\text {heater }}$, is expressed by equation (8). 
$\dot{Q}_{\text {heater }}=\left(T_{\text {heater }}-T_{\text {room }}\right) \cdot \dot{m} \cdot c$,

where $T_{\text {heater }}\left({ }^{\circ} \mathrm{C}\right)$ represents the hot air temperature from the heater, $\dot{m}(\mathrm{~kg} / \mathrm{s})$ the air flow rate, $c(\mathrm{~J} / \mathrm{kgK})$ the specific heat capacity of air and $T_{\text {room }}\left({ }^{\circ} \mathrm{C}\right)$ the room air temperature. In addition, the heater subsystem can be operated considering the PMV index as the reference. The scheme depicted in Figure 2 shows a simple control strategy where the PMV is used as the control reference. By setting the PMV reference to zero, thermal comfort is maintained in the airconditioned room. In this case, the thermostat hysteresis is set to \pm 0.5 [16]. Of course, the comfort variables explained in the previous section need to be measured or estimated. Based on this measured data, the PMV index can be calculated. An illustrative example of this strategy is described in detail in section 4.

\section{$<$ INSERT FIGURE 2 HERE $>$}

The house model takes into consideration two heat flows: the heat flow from the heater, $Q_{\text {heater }}$, and the heat losses to the environment through the walls, windows and roof, $Q_{\text {lossess }}$. The temperature time derivative in the house model is expressed by equation (9).

$\dot{T}_{\text {room }}=\frac{1}{M_{\text {air }} \cdot c} \cdot\left(\dot{Q}_{\text {heater }}-\dot{Q}_{\text {losses }}\right)$

where $\dot{Q}_{\text {losses }}$ is the sum of the heat flow rates $\dot{Q}_{\text {wall }}, \dot{Q}_{\text {window }}$ and $\dot{Q}_{\text {roof }}$. These heat flow rates depend on several parameters such as the outdoor temperature, the total area of the walls, the total area of the windows (which is based on the number of windows), the total air mass inside the house and the heat capacity of the walls, windows and roof. These parameters can be specified in CB-GUI. In addition, the model incorporates a cost calculator that integrates the heat flow over the time and multiplies it by a specified energy cost. In this way it is possible to check the effect of the different model parameters with respect the energy consumption.

\subsection{Graphical user interface}

This section describes the functionalities of the developed interactive tool for the simulation, estimation and real-time monitoring of thermal comfort indices. CB-GUI can be downloaded from http://www.uco.es/grupos/prinia/marioruz/. The main window of CB-GUI is shown in 
Figure 3. It is divided into several differentiated parts (a-f), which can be summarized as follows:

\section{$<$ INSERT FIGURE 3 HERE WITH DOUBLE COLUMN WIDTH $>$}

1. External mode (a). In this section, the TCP/IP Modbus connection parameters are specified. When defining the IP address, the connection port and the sampling period, CB-GUI automatically collects data from available sensors through the TCP/IP Modbus protocol. Thus, PMV and PPD indices are calculated and updated according to a defined sampling period.

2. Simulation mode (b). In this section, the user can choose between two modes: House model and No model. When House model is selected, CB-GUI allows analyzing the temporal evolution of the PMV and PPD thermal comfort indices using the house thermal model described above. The user can introduce all the parameters needed to configure the physical model and the simulation (Fig. 4). In this mode, energy consumption of the heating subsystem is also calculated. By clicking on the Simulate button, the simulation is instantly performed.

\section{$<$ INSERT FIGURE 4 HERE $>$}

Conversely, when No model is selected, PMV and PPD indices are calculated directly. With this mode, the user can manually change the different comfort parameters and observe how PMV and PPD indices are affected.

3. Estimation of the mean radiant temperature (c). This section allows the user to adjust the value of the mean radiant temperature by means of the globe temperature $\left({ }^{\circ} \mathrm{C}\right)$, the globe diameter $(\mathrm{m})$, the air temperature $\left({ }^{\circ} \mathrm{C}\right)$, the emissivity and the air speed $(\mathrm{m} / \mathrm{s})$. On the other hand, it is possible to make the mean radiant temperature equal to the air temperature. Due to the difficulty to measure the mean radiant temperature, this approximation is suggested by some researchers [35][36].

4. Comfort parameters (d). This section enables the user setting the input data for the calculus of PMV and PPD indices. As mentioned before, when CB-GUI is connected to a BMS system, available data from a real installation will be collected, and this section will be unavailable. However, in the simulation mode (with or without thermal model of the house) or 
in the absence of some sensors, (e.g. air speed), the user can manually introduce the values. Moreover, the tool allows choosing between different types of clothing and different physical actions. It is important to note that the clothing level should be calculated based on actual clothing items. Clothing level is probably one of the most important variables in terms of adaptation to a thermal environment. Acting on the clothing level may be very effective to reduce energy consumption [15]. The ASHRAE-55 standard [16] provides a variety of common clothing ensembles and the corresponding clothing level. If the ensemble matches well with one of the ensembles, then the indicated clothing level is used. The developed tool allows to introduce the clothing level numerically or based on common clothing. Note that there might situations with occupants with significantly different garments, and even different metabolic rates. For example, this situation (as referred in the ASHRAE-55 standard [16]) may happen in a restaurant. Customers may have a metabolic rate of 1.0 met, while the servers may have a metabolic rate closer to 2.0 met. Clothing level of course can also vary. Thus, each of these groups of occupants should be considered separately in determining the conditions required for comfort. In these situations, it will not be possible to provide an acceptable level or the same level of comfort to all disparate groups of occupants [16].

Finally, upper and lower thresholds of PMV can be set to define the comfort band. According to these values, two horizontal lines are plotted in the "Real-time PMV estimation" plot (section f), defining the comfort band. The relationship between the defined comfort band and the calculated PMV value will determine possible actions of control.

5. Real time results (e). This section shows the calculated values of the PMV and PPD indices, as well as statistical information, such as the maximum and minimum values, standard deviations and means. In addition, a text message is shown when the calculated PMV is outside the comfort band. Data can also be recorded by activating the radio button Log Data. In this case, a file in .csv format is created, and comfort indices are saved with the defined sampling period. 
6. PMV and PPD plots (f). This section shows the evolution of the PPD and PMV indices. When CB-GUI is connected through the Modbus TCP/IP protocol the plots are updated in real time with the sample period defined in section (a).

As mentioned in the introduction section, there are similar software tools to CB-GUI. Nevertheless, the proposed tool adds the possibility of applying the PMV and PPD indices either to a thermal model or to a real building by means of a control strategy. In situ experimentation with real systems cannot be replaced with simulations, and the practical teaching needs to be also based on real aspects. Experience has shown that students are more motivated to learn new concepts if they are faced with real-life applications [37]. In this sense, from a practical point of view, the connectivity capacity of CB-GUI with a BMS system is also used in the designed course. Students also configure a BMS connection with an installed Modbus TCP/IP gateway and PMV-PPD indices are estimated from a real building [38].

\subsection{Objectives of CB-GUI within the course design}

The course has been designed to achieve specific outcomes that fall into two domains [12]: 1) Planning and definition of the learning objectives; 2) Instruction method to deliver the specific content.

The desired outcomes that students are expected to acquire by applying PBL can be resumed as the ability to carry out the following outcomes [11]:

- Apply knowledge of mathematics, science and engineering.

- Conduct experiments, analyze and interpret data.

- Design systems that match specific needs.

- Function on multidisciplinary teams.

- Identify, formulate, and solve engineering problems.

- Communicate effectively.

- Use the techniques, skills, and modern engineering tools necessary for engineering practice. 
- Recognize the need to engage in lifelong learning.

1) Course learning objectives

At the end of the course, with respect to the use of CB-GUI, students are expected to have done the following:

- Understand the importance of thermal comfort in buildings and how it affects to the occupants.

- Understand the importance of energy consumption in HVAC systems and how it influences the economic spending.

- Ability to design simple simulations with the Matlab/Simulink environment.

- Learn the stages of team functioning and be able to outline the responsibilities of a team.

- Thermal comfort analysis with CB-GUI and reported results of an office building.

2) Instruction method

The presented educational tool is part of the practical sessions planned for the Control Technologies and Laboratory of Process Control subjects, which are taught to enrolled students in the Industrial Engineering Master's degree and the Industrial Electronics Bachelor's degree, respectively, at the University of Cordoba. The PBL tasks for the elaborated practical session are listed in Table II and are directly related to the aforementioned desired outcomes.

\section{$<$ INSERT TABLE 2 HERE $>$}

A good practical session should demonstrate the important theoretical ideas and to reflect important real-life problems with a suitable time scale [39]. In addition, a good visual sensation, easiness to learn and use are desirable features for a software tool. This pedagogical guideline was considered so that the educational tool addresses these requirements in several ways:

- Theoretical ideas: The context of the tool is based on comfort-based control. With this tool, students in control engineering subjects can learn about different scopes of control beyond classical processes. 
- Real-life problem: The students are confronted with an actual real problem. Energy efficiency and sustainable comfort in buildings is one of the main challenges nowadays.

- Visual sensation: The graphical user interface is structured coherently. The information displayed in the main window was reduced as much as possible to facilitate the navigation.

- Suitable time scale: The simulations are immediate so that the students can analyze many possible scenarios in a traditional practical session ( 2 hours).

- Easy to understand and use: The graphical user interface has been designed to be userfriendly. However, the students should be guided in using the tool by the teacher.

\section{ILLUSTRATIVE EXAMPLE}

\subsection{Simulation example}

In this simulation example, a comfort-based control strategy is compared with a typical standard ON-OFF strategy. The aim of this example is to emphasize students how energy consumption of HVAC systems can be significantly decreased with the use of a simple comfort-based strategy. Table 3 summarizes the established model parameters used in the simulation. It is also considered that the occupants wear typical winter clothes $(1 \mathrm{clo})$ and carry out a relaxed physical activity (1.2 met). The external temperature is modeled with a sinusoidal form with an average temperature of $9{ }^{\circ} \mathrm{C}$ and $6{ }^{\circ} \mathrm{C}$ of amplitude, which corresponds to a typical winter day in the city of Cordoba.

\section{$<$ INSERT TABLE 3 HERE $>$}

Simulation results are summarized in Table 4, where the house model was simulated for 48 hours. For the ON-OFF control strategy, two temperature set-points are considered: $24{ }^{\circ} \mathrm{C}$ and $25^{\circ} \mathrm{C}$, both with a hysteresis range of $\pm 2.5^{\circ} \mathrm{C}$. With respect to the comfort-strategy, a dead band of \pm 0.5 is set as recommended by the ASHRAE-55 standard [16].

The simulation results reveal important aspects related with the energy consumption and thermal comfort levels. As can be noted from Table 4, for the ON-OFF control strategy with a set of $25^{\circ} \mathrm{C}$, dissatisfaction levels above $30 \%$ are reached, with an average PPD value of 21.96 
\%. In addition, in this case the PMV index is located outside the upper limit, which indicates a thermal sensation that defined as "slightly warm". The energy consumption is $37.0156 \mathrm{kWh}$, which is approximately $39 \%$ greater than the total energy consumption for the PMV control strategy. Another interesting conclusion is the energy increase for an increment of $1^{\circ} \mathrm{C}$ in the average indoor temperature. For the modeled room, it is $10 \%$ greater when the ON-OFF control strategies are compared with sets of $24{ }^{\circ} \mathrm{C}$ and $25^{\circ} \mathrm{C}$. To achieve PMV values within the \pm 0.5 band, the average indoor temperature obtained is $21.6738^{\circ} \mathrm{C}$, which is lower than the other commented cases. It is important to note the reason of showing ON-OFF strategies with 24 and $25^{\circ} \mathrm{C}$. This is due that, in many occasions, the temperature reference is set too high for adequate thermal comfort, but it is common practice to select temperature set points that quickly rectify the sensation of cold that the occupants perceive. This situation is also highlighted with this example.

\section{$<$ INSERT TABLE 4 HERE $>$}

\subsection{PMV parameters' influence}

Thermal comfort is influenced by six factors and the accuracy of each one will influence the overall accuracy of the calculated PMV [16], [40]. Students were asked to analyze the PMV sensitivity by modifying some of the input parameters while leaving the others fixed. To carry out this task, CB-GUI is executed in No Model mode. In this mode, PPD and PMV values are calculated instantaneously. Special attention is taken to the metabolic rate and clothing level parameters, given the fact there are no direct methods for their calculation.

An error in the metabolic rate estimation can have a significant difference in the estimated PMV value [40]. Given a typical office climate $\left(T_{a i n}=T_{m r}=22^{\circ} \mathrm{C}, v=0.15 \mathrm{~m} \mathrm{~s}^{-1}, r h=50 \%\right)$, Figure 5 shows the sensitivity of the PMV-PPD indexes for a typical business suit (1.0 clo) and for light clothing $(0.6$ clo). As can be seen from the figure, an error in the metabolic rate assessment can easily led to significant errors in the PMV estimation. For example, on the basis of Figure 5 and considering the 1.0 clo curve, a change on the metabolic rate from 1.2 (standing, 
relaxed [15]) to 1.8 (cooking [15], changes the PMV index from -0.0025 to 0.7536 . This PMV value is considered as "slightly warm". Considering the previously described PMV-based control strategy, a temperature set-point below $22{ }^{\circ} \mathrm{C}$ would be reached with the additional energy consumption of the HVAC system. In addition, this new temperature setpoint would cause discomfort in the occupants due to a mistake in the metabolic rate evaluation. Thus, this example highlights the need of an adequate evaluation of the parameters that define the PMV index.

\section{$<$ INSERT HERE FIGURE 5 $>$}

Figure 6 shows the partial correlation of each parameter needed to obtain the PMV index. Students were asked to generate this figure by means of Matlab software. These statistical data were obtained by generating 1000 different combinations from the comfort variables (ranges in parenthesis) $T_{\text {ain }}(15,30), \operatorname{Met}(1,7.8), \operatorname{Clo}(0.36,1), \operatorname{rh}(25,60), v(0.1,2)$. As can be seen from the figure, the metabolic rate and temperature are the most influential parameters, i.e., a positive increment in one of them have a significant increment in the PMV value. These results are intuitive, since the perceived thermal sensation also varies depending on the activity level and the temperature. On the other hand, the only variable with a negative partial correlation is the air velocity.

\section{$<$ INSERT HERE FIGURE 6>}

\subsection{BMS connectivity with a real office building}

In this last part of the case study, CB-GUI was employed as a platform for obtaining experimental data. Thermal comfort of an office building at the University of Córdoba was estimated by means of CB-GUI. The first floor of the office building is air-conditioned with a solar system. Fundamentally, the HVAC system consists of two air-cooled single-effect ammonia/lithium nitrate absorption chillers and $50 \mathrm{~m}^{2}$ of solar thermal collectors. Each absorption machine has its own control system. They communicate each other through a proprietary protocol and through building management system (BMS) with the software tool to 
provide measurement data of temperature sensors. Student were asked to implement the BMS connection between the implemented HVAC system and CB-GUI. The air velocity, humidity and indoor temperature variables were collected from the BMS network for the PMV index estimation. The control information provided in CB-GUI (Fig. 3., part e.) indicated the HVAC on-off cycle to maintain the indoor-air conditions inside the optimal comfort range. The main point of this part was to show the students the main components of a BMS system, i.e, the communication network, the hardware (in this case the HVAC controllers, the solar system and sensors) and the software (CB-GUI working as an upper layer in the control system and the HVAC control programs running in the controllers). The results of these experimental tests with the tool can be consulted in [38].

\section{ASSESMENT AND EVALUATION}

\subsection{Evaluation}

Enrolled students were required to submit an electronic questionnaire. Through the described practical session, the students were asked to express their anonymous opinion of the tool. The main purpose was to analyze the contribution of the tool for the study of human thermal comfort and the application of control strategies. The assessment and evaluation carried out is based on [10], [41], [42], [43].

Questionnaire items are combined in three subscales: "Learning value", "Value added" and "Design usability and easy understanding of the tool". In the following, the purpose of each item is described:

1) Learning value includes questions that try to reflect student's perceptions of how effectively the software tool is designed to learn about thermal comfort concepts and its applicability in buildings.

2) Value added tries to evaluate the use of the tool and the external connection with a BMS system in the sense of a lecture complement. 
3) Design usability and easy understanding of the tool focuses on student's perceptions of the ease and clarity to navigate through the graphical interface.

$<$ INSERT TABLE 5 HERE $>$

\subsection{Results}

The questionnaire is summarized in Table 4. Learning value subscale encompasses the first three items. The next four items are related with Value added. The last three items evaluate the Design usability and easy understanding of the tool. In Table 5, the responses of the students are collected. These responses were rated as strongly agree, agree, neutral, disagree or strongly disagree.

\section{$<$ INSERT TABLE 6 HERE $>$}

\section{$<$ INSERT FIGURE 7 HERE $>$}

Figure 7 details the survey responses of 30 students. The percentage of strongly agree and agree answers was higher compared to the rest. This indicates that the students emphasize the use of the tool to learn and consolidate new concepts of control engineering. Most of them found the graphical user interface user-friendly. Nevertheless, the interactivity level was penalized. The survey results have helped to consider new future enhancements of the tool, some of them are implemented in the downloadable version of CB-GUI.

Although 30 students might not be statistically representative, the results show a certain evidence that the proposed tool helps students in their learning process in control engineering and thermal comfort concepts. A possible bias affecting the results might be that students who made use of the tool are those who attended to class regularly and took lessons seriously. Nevertheless, we received a general positive feedback from the students. They showed a high degree of interest for the use of the tool as complement for lectures and understanding of practical problems related with thermal comfort and the application of control strategies. Future work will be mainly focused on adding new functionalities to the tool, extending the external connection capabilities. 


\section{CONCLUSIONS AND FUTURE WORK}

An educational software tool specifically focused on the learning of thermal comfort has been presented in this paper. The developed tool provides different simulation modes, being also possible the connection with a real system through Modbus TCP/IP. This makes it ideal for using in pedagogy, especially for control engineering practical laboratories. Student feedback and assessment data indicate that the learning objectives were achieved. The student response was satisfactory, showing a high degree of interest for the use of the tool in understanding human thermal comfort indices.

Future work will be mainly focused in the implementation of advanced control strategies with the tool that automatically balance the energy consumption and thermal comfort. Furthermore, it is intended to extend the connectivity capabilities of the tool and consider more advanced comfort models.

\section{ACKNOWLEDGEMENTS}

This work was supported by the Spanish Ministry of Economy and Competitiveness (grant DPI2012-37580-C02-01). This support is gratefully acknowledged.

\section{REFERENCES}

[1] L. Pérez-Lombard, J. Ortiz, and C. Pout, "A review on buildings energy consumption information '," Energy a, vol. 40, pp. 394-398, 2008.

[2] S. Soutullo, R. Enríquez, M. J. Jiménez, and M. R. Heras, "Thermal comfort evaluation in a mechanically ventilated office building located in a continental climate," Energy Build., vol. 81, pp. 424-429, Jul. 2014.

[3] E. Union, Directive 2012/27/EU, Official Journal of the Euopean Union L15 55. 2012, p. 56.

[4] M. Aftab, C. Chau, and P. Armstrong, "Smart Air-Conditioning Control by Wireless Sensors : An Online Optimization Approach," in e-Energy'13 4th International Conference on Future Energy Systems, 2013, pp. 225-236.

[5] M. L. Ruz, J. Garrido, F. Vázquez, and F. Morilla, "A hybrid modeling approach for steady-state optimal operation of vapor compression refrigeration cycles," Appl. Therm. Eng., vol. 120, pp. 74-87, Jun. 2017.

[6] S. Atthajariyakul and T. Leephakpreeda, "Real-time determination of optimal indoor-air condition for thermal comfort, air quality and efficient energy usage," Energy Build., vol. 36, no. 7, pp. 720-733, Jul. 2004.

[7] K. H. Yang and C. H. Su, "An Approach to Building Energy Savings Using the PMV Index," Build. Environ., vol. 32, no. 1, pp. 25-30, 1997. 
[8] M. M. Gouda, S. Danaher, and C. P. Underwood, "Thermal comfort based fuzzy logic controller,” Build. Serv. Eng. Res. Technol., vol. 22, no. 4, pp. 237-253, 2001.

[9] W. L. Tse and A. T. P. So, "Implementation of comfort-based air-handling unit control algorithms," in 2000 ASHRAE Winter Meeting, 2000.

[10] J. Sánchez, S. Dormido, R. Pastor, and F. Morilla, “A Java/Matlab-Based Environment for Remote Control System Laboratories: Illustrated With an Inverted Pendulum," IEEE Trans. Educ., vol. 47, no. 3, pp. 321-329, 2004.

[11] R. M. Felder and R. Brent, "Designing and teaching courses to satisfy the ABET engineering criteria," vol. 92, no. 1, pp. 7-25, Jan. 2003.

[12] D. Santos-Martin, J. Alonso-Martinez, J. Eloy-Garcia Carrasco, and S. Arnaltes, "Problem-Based Learning in Wind Energy Using Virtual and Real Setups," IEEE Trans. Educ., vol. 55, no. 1, pp. 126-134, 2012.

[13] P. O. Fanger, Thermal Comfort: Analysis and Applications in Environmental Engineering. McGraw-Hill, 1970.

[14] S. Schiavon, T. Hoyt, and A. Piccioli, "Web application for thermal comfort visualization and calculation according to ASHRAE Standard 55," Build. Simul., vol. 7, pp. 321-334, 2014.

[15] ASHRAE, “ASHRAE Thermal Comfort Tool,” 2011. [Online]. Available: http://comfort.cbe.berkeley.edu/.

[16] ASHRAE, “ANSI/ASHRAE Standard 55-2017, Thermal Environmental Conditions for Human Occupancy." American Society of Heating, Refrigerating and Air-Conditioning Engineers, Atlanta. GA., 2017.

[17] S. Liu, S. Schiavon, A. Kabanshi, and W. W. Nazaroff, "Predicted percentage dissatisfied with ankle draft," Indoor Air, vol. 27, no. 4, pp. 852-862, Jul. 2017.

[18] S. Schiavon, D. Rim, W. Pasut, and W. W. Nazaroff, "Sensation of draft at uncovered ankles for women exposed to displacement ventilation and underfloor air distribution systems," Build. Environ., vol. 96, pp. 228-236, Feb. 2016.

[19] M. Milne, R. Liggett, A. Benson, and Y. Bhattacharya, "Climate Consultant 4 . 0 Develops Design Guidelines for Each Unique Climate," in American Solar Energy Society Meeting, 2009.

[20] “EnergyPlus. U.S. Department of Energy's (DOE) Building Technologies Office (BTO), and managed by the National Renewable Energy Laboratory (NREL)." [Online]. Available: https://energyplus.net/. [Accessed: 10-Feb-2018].

[21] "Dassault Systèmes. Dymola Systems Engineering," 2018. [Online]. Available: https://www.3ds.com/products-services/catia/products/dymola. [Accessed: 12-Feb2018].

[22] "Modelica official website." [Online]. Available: https://www.modelica.org. [Accessed: 14-Feb-2018].

[23] B. Michaelsen and J. Eiden, "Human Comfort Modelica-Library Thermal Comfort in Buildings and Mobile Applications," Proc. 7th Model. Conf. Como, Italy, Sep. 20-22, 2009.

[24] S. Wischhusen, "Modelling and Calibration of a Thermal Model for an Automotive Cabin using HumanComfort Library," Proc. 9th Int. Model. Conf. Sept. 3-5, 2012, Munich, Ger.

[25] U.-E. I. 7730:2006, Ergonomics of the thermal environment - Analytical determination 
and interpretation of thermal comfort using calculation of the PMV and PPD indices and local thermal comfort criteria. 2006.

[26] R. Yao, B. Li, and J. Liu, "A theoretical adaptive model of thermal comfort - Adaptive Predicted Mean Vote ( aPMV )," Build. Environ., vol. 44, no. 10, pp. 2089-2096, 2009.

[27] M. Humphreys, "Outdoor temperatures and comfort indoors," Build. Res. Pract., vol. 6, no. 2, pp. 92-105, 1978.

[28] AENOR, ISO 7730:2005, Ergonomics of the Thermal Environment-Analytical Determination and Interpretation of Thermal Comfort Using Calculation of the PMV and PPD Indices and Local Thermal Comfort Criteria. Geneva: International Organization for Standardization. 2005.

[29] C. Croitoru, I. Nastase, F. Bode, A. Meslem, and A. Dogeanu, "Thermal comfort models for indoor spaces and vehicles - Current capabilities and future perspectives," Renew. Sustain. Energy Rev., vol. 44, 2015.

[30] M. Castilla, J. Domingo Álvarez, F. Rodríguez, and M. Berenguel, Comfort Control in Buildings. Springer-Verlag, 2014.

[31] B. Givoni, Passive and low energy cooling of buildings. New York, New York, USA: Wiley-Blackwell, 1994.

[32] J. A. Orosa, "Research on the Origins of Thermal Comfort," Eur. J. Sci. Res., vol. 34, no. 4, pp. 561-567, 2009.

[33] L. Möller and L. Sörensen, "Thermodynamical Modeling of a Car Cabin.” 2011.

[34] MathWorks, "House heating system." [Online]. Available: https://es.mathworks.com/help/physmod/simscape/examples/house-heating-system.html.

[35] Y. Farzaneh and A. a. Tootoonchi, "Controlling automobile thermal comfort using optimized fuzzy controller," Appl. Therm. Eng., vol. 28, no. 14-15, pp. 1906-1917, Oct. 2008.

[36] K. L. Ku, J. S. Liaw, M. Y. Tsai, and T. S. Liu, "Automatic Control System for Thermal Comfort Based on Predicted Mean Vote and Energy Saving," IEEE Trans. Autom. Sci. Eng., pp. 1-6, 2014.

[37] D. Cooper and D. Fina, "Training simulators enhance process control education," in Proceedings of the 1999 American Control Conference (Cat. No. 99CH36251), 1999, vol. 2, no. June, pp. 997-1001.

[38] M. L. Ruz, S. Fragoso, D. Rodríguez, and F. Vázquez, "Real-time estimation of thermal comfort indices in an office building with a solar powered HVAC system," in $23 r d$ Mediterranean Conference on Control and Automation, 2015, pp. 803-808.

[39] J. G. Balchen, M. Handlykken, and A. Tysso, "The need for better laboratory experiments in control engineering education," in 8th IFAC World Congress, 1981, pp. 3363-3368.

[40] G. Havenith, I. Holmér, and K. Parsons, "Personal factors in thermal comfort assessment: Clothing properties and metabolic heat production," Energy Build., vol. 34, no. 6, 2002.

[41] R. Dormido et al., "Development of a web-based control laboratory for automation technicians: The three-tank system," IEEE Trans. Educ., vol. 51, no. 1, pp. 35-44, 2008.

[42] S. Fragoso, M. L. Ruz, J. Garrido, F. Vázquez, and F. Morilla, "Educational software tool for decoupling control in wind turbines applied to a lab-scale system," Comput. Appl. Eng. Educ., vol. 24, no. 3, pp. 400-411, 2016. 
[43] D. C. Morales, J. E. Jiménez-Hornero, F. Vázquez, and F. Morilla, "Educational tool for optimal controller tuning using evolutionary strategies," IEEE Trans. Educ., vol. 55, no. 1, pp. 48-57, 2012. 


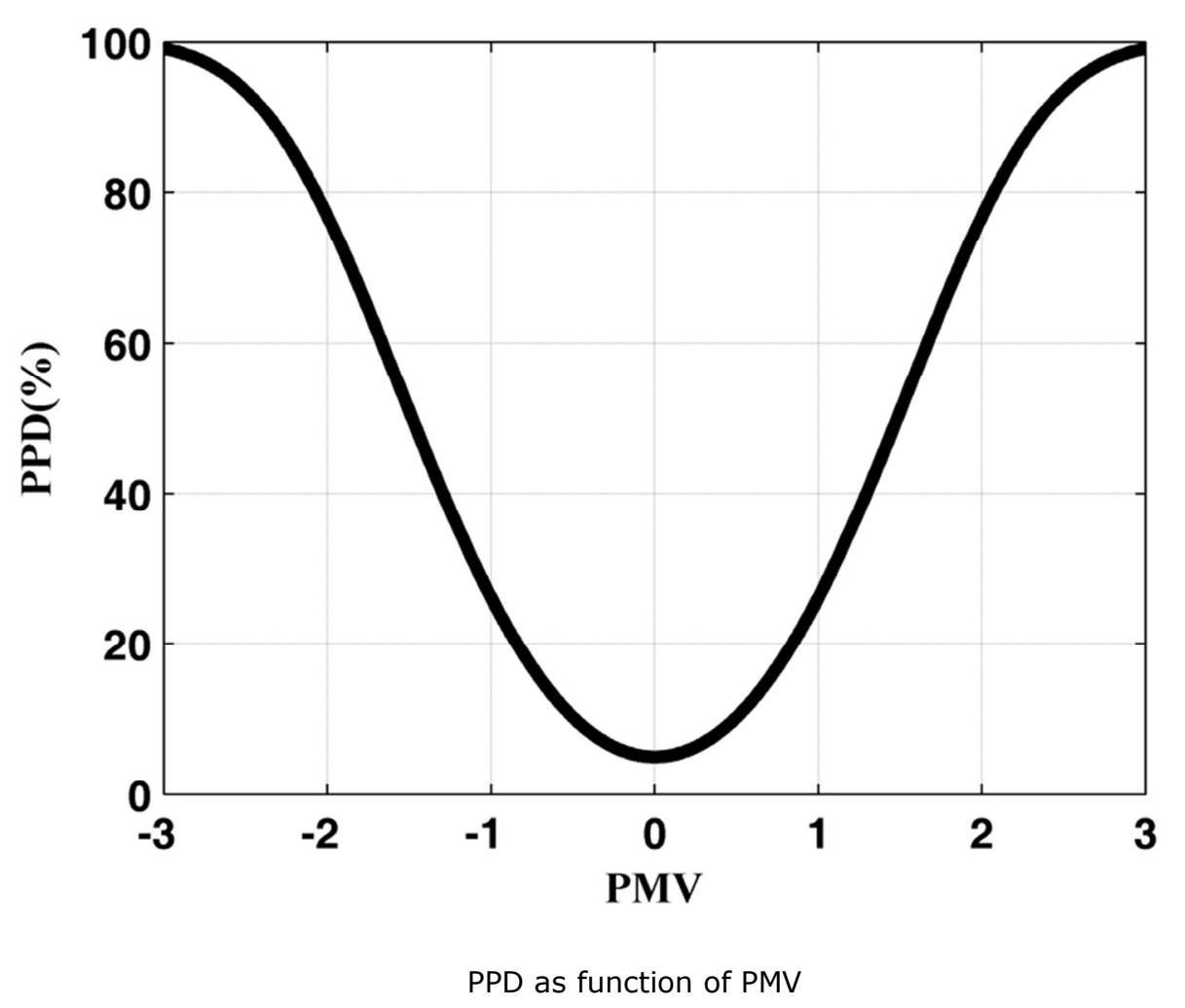

$77 \times 57 \mathrm{~mm}(300 \times 300$ DPI) 


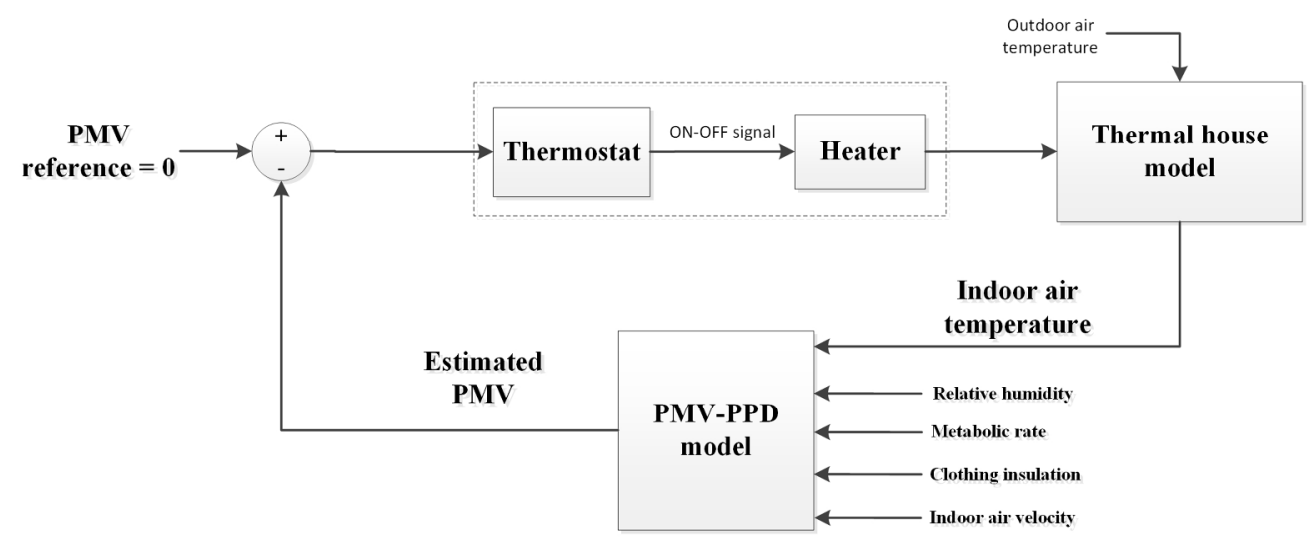

PMV-based control strategy

$198 \times 81 \mathrm{~mm}(300 \times 300$ DPI $)$ 


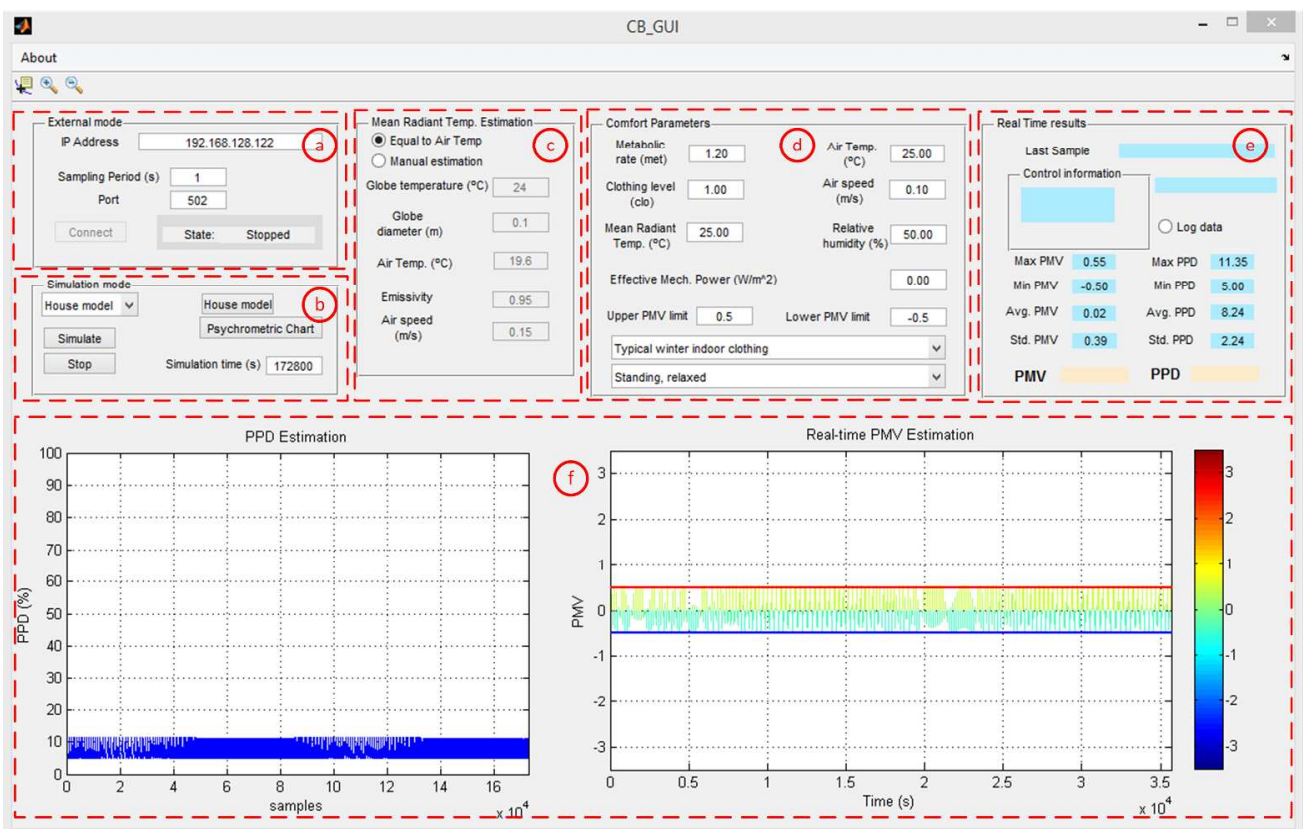

\section{CB-GUI main window}

$315 \times 200 \mathrm{~mm}(300 \times 300 \mathrm{DPI})$ 


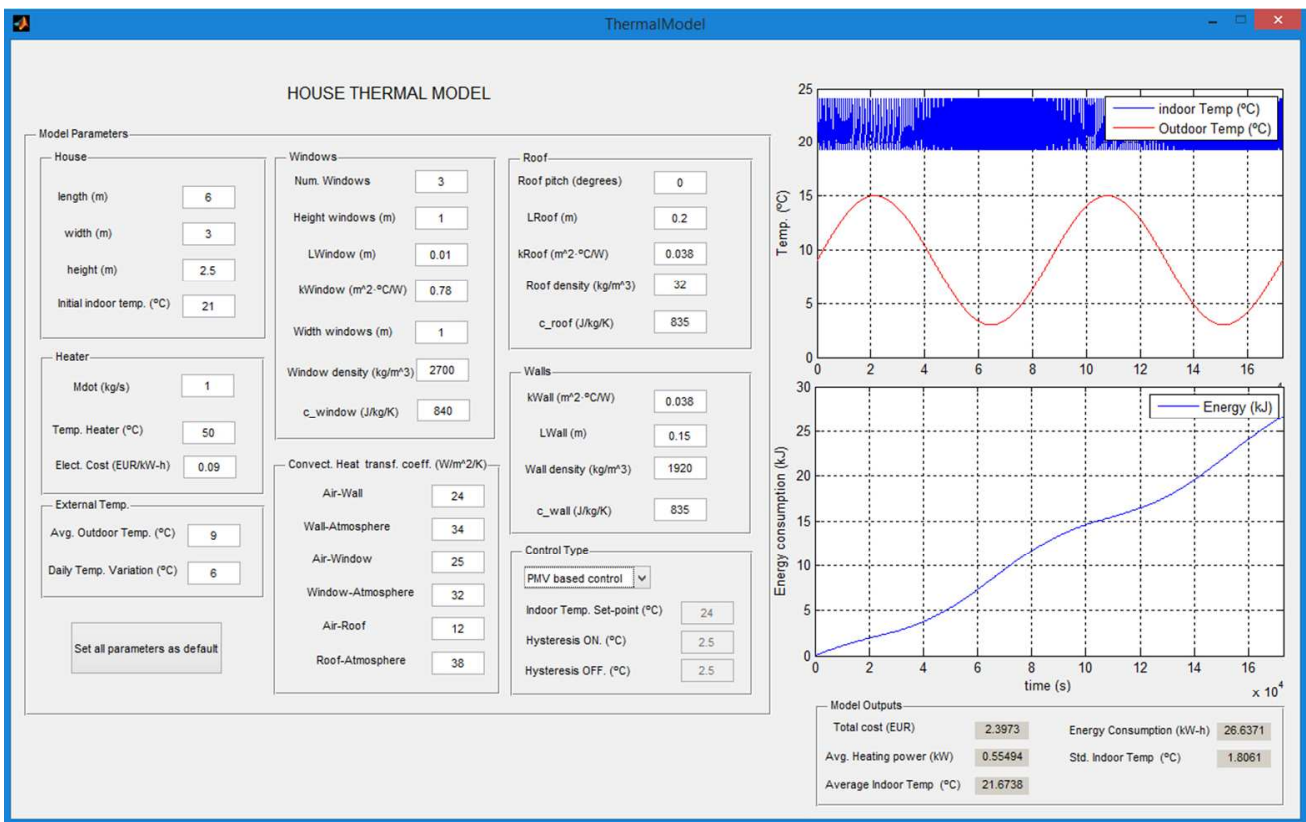

Simulation window

$106 \times 66 \mathrm{~mm}(300 \times 300$ DPI $)$

John Wiley \& Sons 

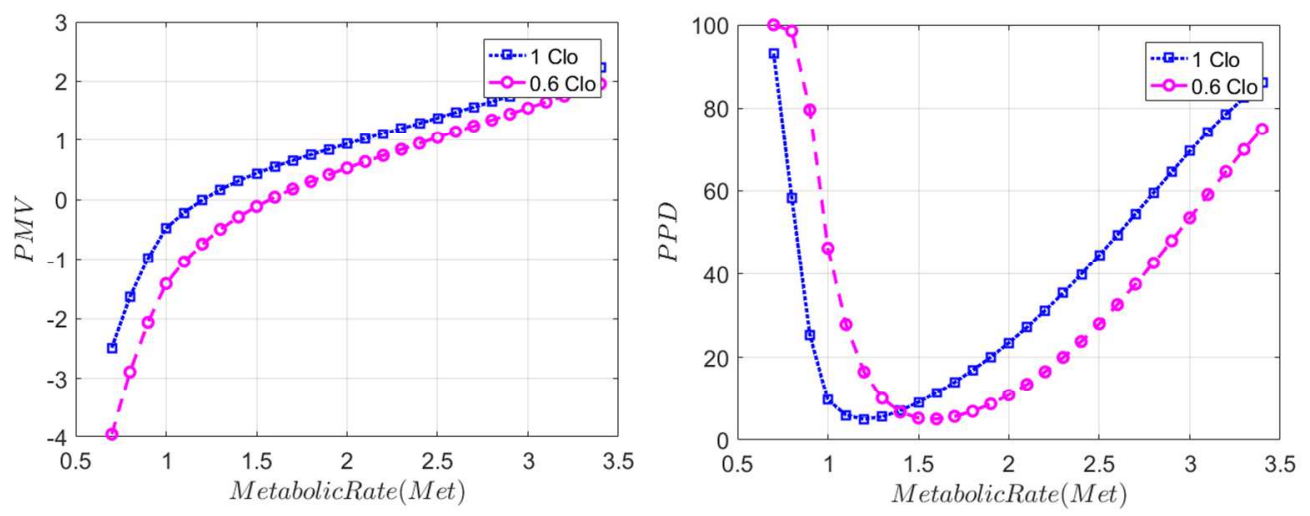

Relationship between metabolic rate and PMV and PPD values for typical office climates. Sensitivity of PMVPPD indexes for the clothing insulation parameter (Clo)

$110 \times 43 \mathrm{~mm}(300 \times 300 \mathrm{DPI})$ 


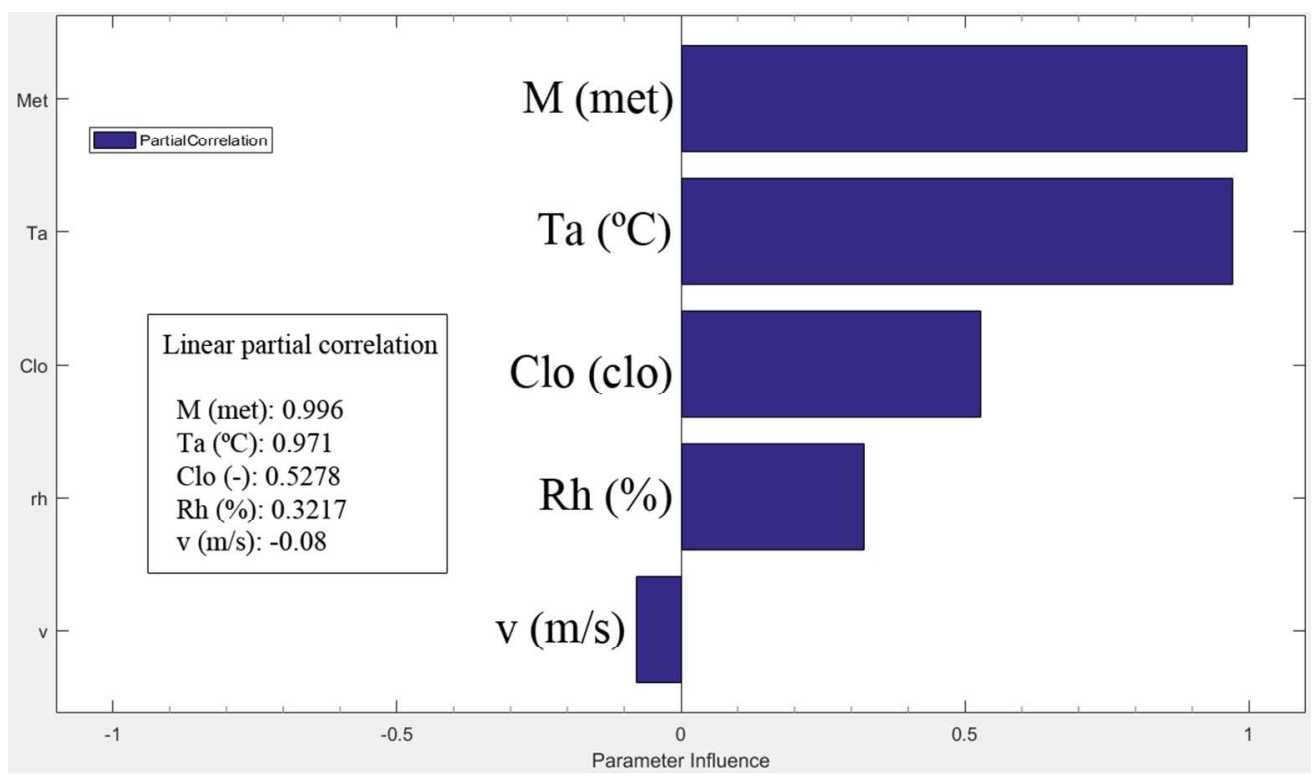

Partial correlation between PMV and each input parameter $100 \times 58 \mathrm{~mm}(300 \times 300$ DPI $)$ 


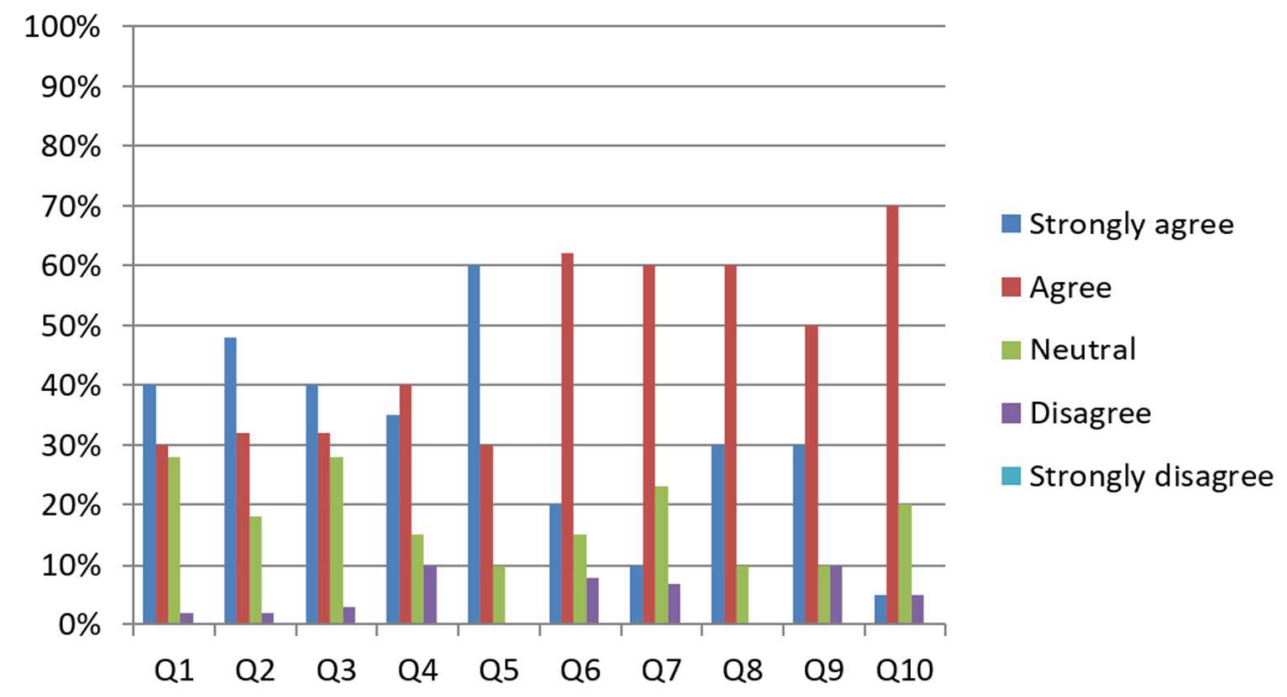

Student survey answers

$91 \times 50 \mathrm{~mm}(300 \times 300$ DPI $)$ 
TABLE 1. THERMAL SENSATION SCALE

\begin{tabular}{cc}
\hline \hline PMV & Sensation \\
\hline+3 & Hot \\
\hline+2 & Warm \\
\hline+1 & Slightly warm \\
\hline 0 & Neutral \\
\hline-1 & Slightly cool \\
\hline-2 & Cool \\
\hline-3 & Cold \\
\hline \hline
\end{tabular}


TABLE 2. INSTRUCTION METHOD

\begin{tabular}{ccc}
\hline \hline Lecture & Thermal comfort concepts & Outcome 1,2,4,5 \\
\hline PBL.task 1 & $\begin{array}{c}\text { Learning the use of CB-GUI in a } \\
\text { guided way }\end{array}$ & Outcome 7 \\
\hline PBL.task 2 & $\begin{array}{c}\text { Solve the proposed problem for } \\
\text { the instructor }\end{array}$ & Outcome 1,2,3,4,7 \\
\hline PBL.task 3 & $\begin{array}{c}\text { Analyzing a real situation with } \\
\text { the BMS connection }\end{array}$ & Outcomes 1,7,8 \\
\hline PBL.task 4 & $\begin{array}{c}\text { Present the problem and solution } \\
\text { in a final report }\end{array}$ & Outcome 4,6 \\
\hline
\end{tabular}


TABLE 3. PARAMETERS OF THE HOUSE MODEL

\begin{tabular}{|ll|}
\hline \hline Parameter & Value \\
\hline House length $(l)$ & $6 \mathrm{~m}$ \\
\hline House width $(w)$ & $3 \mathrm{~m}$ \\
\hline House height $(h)$ & $2.5 \mathrm{~m}$ \\
\hline Wall thickness $\left(D_{\text {wall }}\right)$ & $0.15 \mathrm{~m}$ \\
\hline Wall density $\left(d_{\text {wall }}\right)$ & $1920 \mathrm{~kg} / \mathrm{m}^{3}$ \\
\hline Wall specific heat $\left(c_{\text {wall }}\right)$ & $835 \mathrm{~J} /(\mathrm{kg} \mathrm{K})$ \\
\hline Wall thermal conductivity $\left(k_{1}\right)$ & $0.038 \mathrm{~W} /(\mathrm{m} \mathrm{K})$ \\
\hline Number of windows $\left(n_{\text {window })}\right)$ & 3 \\
\hline Window height $\left(h_{\text {window }}\right)$ & $1 \mathrm{~m}$ \\
\hline Window width $\left(w_{\text {window }}\right)$ & $1 \mathrm{~m}$ \\
\hline Window thickness $\left(D_{\text {window }}\right)$ & $0.01 \mathrm{~m}$ \\
\hline Window density $\left(d_{\text {window }}\right)$ & $2700 \mathrm{~kg} / \mathrm{m}^{3}$ \\
\hline Window specific heat $\left(c_{\text {window }}\right)$ & $840 \mathrm{~J} /(\mathrm{kg} \mathrm{K})$ \\
\hline Window thermal conductivity $\left(k_{2}\right)$ & $0.78 \mathrm{~W} /(\mathrm{m} \mathrm{K})$ \\
\hline Roof pitch $(\theta)$ & $0 \mathrm{deg}$ \\
\hline Roof thickness $\left(D_{\text {roof }}\right)$ & $0.2 \mathrm{~m}$ \\
\hline Roof density $\left(d_{\text {roof }}\right)$ & $32 \mathrm{~kg} / \mathrm{m}^{3}$ \\
\hline Roof thermal conductivity $\left(k_{3}\right)$ & $0.038 \mathrm{~W} /(\mathrm{m} \mathrm{K})$ \\
\hline Roof specific heat $\left(c_{\text {roof }}\right)$ & $835 \mathrm{~J} /(\mathrm{kg} \mathrm{K})$ \\
\hline $\begin{array}{l}\text { Air-wall convective heat transfer coefficient } \\
\left(h_{1}\right)\end{array}$ & $24 \mathrm{~W} /\left(\mathrm{m}^{2} \mathrm{~K}\right)$ \\
\hline $\begin{array}{l}\text { Wall-atmosphere convective heat transfer } \\
\text { coefficient }\left(h_{2}\right)\end{array}$ & $34 \mathrm{~W} /\left(\mathrm{m}^{2} \mathrm{~K}\right)$ \\
\hline $\begin{array}{l}\text { Air-window convective heat transfer } \\
\text { coefficient }\left(h_{3}\right)\end{array}$ & $25 \mathrm{~W} /\left(\mathrm{m}^{2} \mathrm{~K}\right)$ \\
\hline $\begin{array}{l}\text { Window-atmosphere convective heat } \\
\text { transfer coefficient }\left(h_{4}\right)\end{array}$ & $32 \mathrm{~W} /\left(\mathrm{m}^{2} \mathrm{~K}\right)$ \\
\hline $\begin{array}{l}\text { Air-roof convective heat transfer coefficient } \\
\left(h_{5}\right)\end{array}$ & $12 \mathrm{~W} /\left(\mathrm{m}^{2} \mathrm{~K}\right)$ \\
\hline $\begin{array}{l}\text { Roof-atmosphere convective heat transfer } \\
\text { coefficient }\left(h_{6}\right)\end{array}$ & $38 \mathrm{~W} /\left(\mathrm{m}^{2} \mathrm{~K}\right)$ \\
\hline Air density $(\rho)$ & $1.2250 \mathrm{~kg} / \mathrm{m}^{3}$ \\
\hline Air specific heat $\left(c_{\text {air }}\right)$ & \\
\hline \hline
\end{tabular}


TABLE 4. SIMULATION RESULTS

\begin{tabular}{|c|c|c|c|c|c|c|}
\hline Control strategy & $\begin{array}{c}\text { Avg. Indoor } \\
\text { Temp. }\left({ }^{\circ} \mathbf{C}\right)\end{array}$ & $\begin{array}{c}\text { Total energy } \\
\text { consumption } \\
(\mathbf{k W h})\end{array}$ & $\begin{array}{c}\text { Avg. Heating } \\
\text { power (kW) }\end{array}$ & $\begin{array}{c}\text { PPD (mean, } \\
\text { max) }\end{array}$ & $\begin{array}{c}\text { Avg. } \\
\text { PMV }\end{array}$ & $\begin{array}{c}\text { Total } \\
\text { electrical cost } \\
\text { (EUR) }\end{array}$ \\
\hline ON-OFF & 25.1127 & 37.0156 & 0.7711 & $(21.96,43.36)$ & 0.79 & 3.3314 \\
\hline ON-OFF & 23.9463 & 33.6063 & 0.7001 & $(14.28,28.24)$ & 0.53 & 3.0246 \\
\hline PMV-based & 21.6738 & 26.6371 & 0.5549 & $(8.25,11.33)$ & 0.03 & 2.3973 \\
\hline
\end{tabular}


TABLE 5. STUDENT QUESTIONNAIRE

\begin{tabular}{ll}
\hline \hline \multicolumn{2}{l}{ Learning value } \\
\hline Q1 & Did the tool enhance your ability to understand the theoretical material in a new way? \\
Q2 & Did the tool help you to visualize the new concepts of thermal comfort? \\
Q3 & Did you think that you have gained as much information as you would from a lecture explanation? \\
\hline Value added & \\
\hline Q4 & Did the tool help you to improve your theoretical knowledge of comfort-based control? \\
Q5 & Were you able to work through experiences in a way that could not have been possible by attending a traditional \\
& lab? \\
Q6 & Were you able to understand the possibility of application of different control strategies over HVAC systems to \\
Q7 & improve the thermal comfort? \\
\hline Design usability and easy understanding of the tool \\
\hline Q8 & Was the CB-GUI easy to understand and use? \\
Q9 & Did you think that the graphical interface user is user-friendly? \\
Q10 & The ideas and concepts within the tool were clearly presented and easy to follow? \\
\hline \hline
\end{tabular}


TABLE 6. STUDENT RESPONSES OF THE TOOL SURVEY PER SUBSCALE $($ NUMBER OF STUDENTS = 30)

\begin{tabular}{|c|c|c|c|c|c|}
\hline Group items & $\begin{array}{c}\text { Strongly } \\
\text { agree }\end{array}$ & Agree & Neutral & Disagree & Strongly disagree \\
\hline Learning value (Q1,Q2,Q3) & $42.66 \%$ & $31.33 \%$ & $23.66 \%$ & $2.33 \%$ & $0 \%$ \\
\hline Value added (Q4, Q5, Q6, Q7) & $30.25 \%$ & $48 \%$ & $15.75 \%$ & $6.25 \%$ & $0 \%$ \\
\hline $\begin{array}{l}\text { Design usability and easy } \\
\text { understanding of the tool (Q8, } \\
\text { Q9, Q10) }\end{array}$ & $21.66 \%$ & $60 \%$ & $13.33 \%$ & $5 \%$ & $0 \%$ \\
\hline
\end{tabular}

